\title{
Chapter 3 \\ Methods to Monitor and Mitigate Wildlife Mortality in Railways
}

\author{
Filipe Carvalho, Sara M. Santos, António Mira and Rui Lourenço
}

\begin{abstract}
Recording wildlife mortality on railways is challenging as they have narrow corridors and lower accessibility. To improve mitigation measures, surveys must be systematic and their frequency depending on the targeted species traits and biology. To obtain unbiased estimates in diverse contexts, the data should be corrected using mortality estimators. Mitigation measures must avoid that animals remain on the tracks, as trains cannot be instantly stopped. Box culverts, amphibian tunnels, and under- or overpasses allow a safe crossing, whereas exclusion fences, olfactory repellents, sound signals and sound barriers prevent the crossing of railways. Habitat management in railway verges improves the animal capability to evade trains.
\end{abstract}

Keywords Bias sources - Mitigation - Monitoring methods - Monitoring plan • Mortality estimators

Filipe Carvalho and Rui Lourenço have contributed equally to this chapter.

F. Carvalho $(\square) \cdot$ S.M. Santos $\cdot$ A. Mira

CIBIO/InBIO, Centro de Investigação em Biodiversidade e Recursos Genéticos,

Universidade de Évora, Pólo de Évora, Casa do Cordovil $2^{\circ}$ Andar,

7000-890 Évora, Portugal

e-mail: filipescpcarvalho@gmail.com

F. Carvalho

Department of Zoology and Entomology, School of Biological and Environmental Sciences, University of Fort Hare, Private Bag X1314, Alice 5700, South Africa

A. Mira

Unidade de Biologia da Conservação, Departamento de Biologia,

Universidade de Évora, Mitra, 7002-554 Évora, Portugal

R. Lourenço

LabOr - Laboratório de Ornitologia, ICAAM-Instituto de Ciências Agrárias e Ambientais

Mediterrânicas, Universidade de Évora, Pólo da Mitra, 7002-554 Évora, Portugal

(C) The Author(s) 2017

L. Borda-de-Água et al. (eds.), Railway Ecology,

DOI 10.1007/978-3-319-57496-7_3 


\section{Monitoring Wildlife Mortality in Railways: General Approaches}

Railway mortality can negatively affect some species. It is, therefore, crucial to accurately monitor casualties that will reveal areas of high killing rates (i.e., hotspots). This will allow a correct assessment of environmental factors influencing higher mortality rates and the application of proper mitigation measures (Gunson et al. 2011). However, most of our understanding on railway impacts comes from a small number of studies in North America and Europe on a few species, primarily large mammals, such as moose and bears (e.g., Dorsey et al. 2015).

\section{Why Is Monitoring Important?}

Ideally, before implementing any linear infrastructure, it is advisable to assess its possible impacts (e.g., vegetation removal, soil movement, noise, light pollution, etc.) in adjacent areas. In addition, species richness and abundance must be recorded to establish a baseline to identify possible conservation concerns (e.g., extinction risk of rarer species) (van der Grift et al. 2013). This is especially relevant when the infrastructure is to be placed across a natural protected area, encompassing several ecosystems (Dorsey et al. 2015). Then, during and after construction, a monitoring plan aiming to measure the impact of collisions, electrocution, rail entrapment, use of culverts, and other aspects of the railway, is crucial for forecasting and understanding the behavioral responses of animals living in the vicinity (Iuell et al. 2003; van der Grift et al. 2013). Therefore, based on the results obtained, we endeavor to set up the best mitigation solutions for each situation.

So far, most research and monitoring studies have assessed the use and effectiveness of wildlife crossing structures (Hunt et al. 1987; Rodríguez et al. 1996). To counteract this, we focus on the monitoring of wildlife mortality, as it is the most visible direct impact of linear infrastructures (van der Grift et al. 2013). Some impacts of railways differ from those of roads for example, the casualties from electrocution, rail entrapment and wire strikes (Dorsey et al. 2015), which suggests the need for specific monitoring programs.

\section{Designing a Wildlife Mortality Monitoring Plan for Railways}

Monitoring is limited by practical considerations of cost and feasibility, so a survey of all species is unrealistic (Rytwinski et al. 2015; van der Grift et al. 2013). In fact, costs are one of the main reasons that the state of the habitats and species crossed by a railway are often not assessed. However, regardless of the cost considerations, the 
impacts of new projected linear infrastructures must always be assessed. Thus, measures should be taken before construction starts, and then during the construction phases to mitigate those impacts on wild species present: this includes paying attention to fences (adequate mesh size, buried, and without holes), fauna passes, and, mainly because of amphibians, the preservation of existing ponds (Iuell et al. 2003). Usually, a monitoring plan must follow four important steps: (1) the choice of the target species; (2) the selection of the spatio-temporal scale of the study; (3) the selection of methods to estimate mortality; and (4) the standardization of the variables influencing wildlife mortality, so that they are easily replicable and comparable (Roedenbeck et al. 2007; van der Grift et al. 2013). To achieve these goals, the co-operation between railway company workers, stakeholders and wildlife researchers at all stages of the monitoring plan (Iuell et al. 2003; Roedenbeck et al. 2007).

\section{Selecting the Target Species}

The selection of the species to be monitored depends on their traits (e.g., vagility, conservation status, or sensitivity to fragmentation), on features of the landscape crossed by the railway, and on the characteristics of the railway. For instance, if the railway has overhead electric lines and pylons special care should be taken with birds and bat species (Peña and Llama 1997; Rose and Baillie 1989; SCV 1996); if there is a risk of entrapment inside the rail lines, low vagile reptiles (e.g., turtles) and amphibians (e.g., toads) must be prioritized (Kornilev et al. 2006; Pelletier et al. 2006).

Species that show strong responses toward linear infrastructures and traffic flow, such as carnivores and ungulates, are often selected as target species. These animals are good models for evaluating the factors influencing mortality, because they have large individual territories and large daily and seasonal movements that increase the probability of crossing and of being hit by a train (Iuell et al. 2003; van der grift et al. 2013). Some habitat specialists, like forest-dwelling ones (e.g., the tawny owl Strix aluco), should also be considered in this group as they often use specific corridors that cross railways, thus increasing their risk of collision.

Relying on larger species (or species with high visibility) may increase the detection probability because recording wildlife mortality on railways is often harder than on roads, as railways have lower accessibility, narrower corridors, lack of lateral dirt roads, and a highly variable topographic profile (Dorsey 2011; Wells et al. 1999). In addition, choosing abundant species will likely increase sample sizes, and thus the power of the analyses and some species might serve as a proxy for rarer ones that allows obtaining crucial data that otherwise will be not possible (e.g., Roedenbeck et al. 2007). 


\section{Selecting the Spatio-Temporal Scale}

The rationale for selecting the spatio-temporal scales depends on the species to be monitored (Roedenbeck et al. 2007; van der Grift et al. 2013). Large animals with large home ranges and daily movements require the survey of a railway stretch large enough (e.g., $30 \mathrm{~km}$ ) to reflect their spatial requirements (Iuell et al. 2003; Seiler and Helldin 2006). By contrast, if we aim to study a local amphibian population during seasonal migrations, a $1 \mathrm{~km}$ railway stretch can be reasonable (Hels and Buchwald 2001). Another important issue is the habitat preference. If the target species is forest-dwelling, we must focus on stretches crossing forests (Iuell et al. 2003). For more general species, the railway stretch selection should cover and reflect a hierarchical distribution and abundance of the existing habitats (van der Grift et al. 2013) or, alternatively, we may choose different railway stretches, each representing a different habitat (Roedenbeck et al. 2007). If a species shows clear seasonal movements with a high probability of railway crossings at certain periods of the year (e.g., amphibian breeding season migrations), then wildlife mortality studies should focus on those periods.

\section{Estimating the Number of Casualties on Railways}

After assessing the baseline situation in a given region, the following guidelines are important to achieve an appropriate monitoring plan. In electrified railways, besides the mortality due to train-collisions (almost all vertebrate groups), we also expect mortality due to overhead electric line collisions (birds and bats) and electrocution at cables and pylons (mainly birds). Once the sources of mortality are established, we should adopt the most practical prospecting methods (e.g., on foot, on foot with a search dog, or using a motor vehicle) according to the railway features (width, train speed and volume, vegetation on verges, topography, etc.) (Dorsey et al. 2015; SCV 1996).

Counting dead animals along railways is more challenging than on roads because railways often cross remote areas and their accessibility is often difficult (tunnels, steep topography, etc.) (Dorsey et al. 2015; Wells et al. 1999). Therefore, most studies report counts obtained by the transportation agency personnel, such as, train drivers and maintenance workers, who often lack wildlife experience, leading to inaccurate identifications and underestimation of the mortality (Wells et al. 1999).

An important issue is the sampling effort required in each situation to effectively detect patterns of causalities (Costa et al. 2015; Santos et al. 2011, 2015). As recommended for roads, railway surveys should be carried out early in the morning (to reduce scavenging, but see also sources of bias below), preferably by two experienced observers walking at specified railway stretches, one on each side of the rail (Peña and Llama 1997), and covering a $10 \mathrm{~m}$ sight strip whenever logistically possible. The use of a vehicle could be a better choice if parallel dirty roads exist (at least on one side), and in cases where the surveyed stretch is too long 
$(>10 \mathrm{~km}$ ), but their detectability as proved to be lower (Garrah et al. 2015). Once a carcass is found, and depending on its state of decay, several variables should be recorded: species, age, sex, GPS location, time of day, weather conditions, position on the railway (verges, between lines, rock ballast, etc.), and surrounding habitat (Santos et al. 2011; Wells et al. 1999).

Surveys should be systematic, but their temporal frequency depends on species traits and biology. For small animals such as passerines, small mammals or bats, daily surveys are needed to reduce bias on estimates due to lower carcass persistence time (Santos et al. 2011, 2015). Santos et al. (2011) showed in a road study that sampling at intervals greater than one day results in the loss of $60 \%$ of the casualties for small animals $(<500 \mathrm{~g})$, and reaches 73 and $85 \%$ for lizards and bats, respectively. By contrast, they found that larger animals ( $>500 \mathrm{~g}$, e.g., birds of prey and carnivores) persist for more than two days on average, which can be used as a baseline for their monitoring (Santos et al. 2011). In order to obtain a good balance among costs and survey frequency, the priority should be given to the animals' activity peaks, including those during dispersal, migration, and hunting seasons (Costa et al. 2015; Stevens and Dennis 2013). After the beginning of the railway operations, and in order to get a good evaluation of mortality estimates, monitoring should cover a minimum period of 3 years, so that animals adapt to the new environment (Iuell et al. 2003).

On electrified railways the risk of bird and bat mortality increases due to collisions with the overhead electric lines. Additionally, the electrocution of birds can occur at pylons and wherever the cable isolation has flaws (Kušta et al. 2011; Peña and Llama 1997). Because overhead electric lines are placed at the sides of the rails, animals killed by electrocution may be projected further away than those suffering collisions with trains, thus decreasing their detectability. Accordingly, to obtain accurate estimates on mortality when there are electric components (overhead electric lines and pylons), surveys should be done daily, and if possible, supported by search dogs, as these dogs have been shown to be more efficient than humans at detecting carcasses under power lines (73 vs. 20\%) and at wind farms (Mathews et al. 2013).

\section{Review of the Methods Used on Wildlife Mortality Surveys}

Most studies addressing mortality on railways rely on incidental reports provided by the railway staff (van der Grift and Kuijsters 1998). Few have described their methods exhaustively (Seiler and Helldin 2006), and most do not report the monitoring frequency (e.g., Cserkész and Farkas 2015; van der Grift and Kuijsters 1998), or the methodology used (Jaren et al. 1991). Typically, studies used one of the following survey methods:

\section{- Surveys by rail companies' workers and non-expert citizens}

These surveys are characterized by fortuitous observations. Reports of collisions are often done by train drivers, and occasionally by maintenance crew personnel, who 
visit the railways to maintain the rails, electric components, or fences (Huijser et al. 2012), thus occasionally recording casualties but without a fixed periodicity (Gundersen et al. 1998; Kušta et al. 2014; SCV 1996). Recently, to minimize bias and identify hotspots properly, some studies have used reports of train drivers obtained systematically, with information on both the species and location of the accident (Dorsey 2011; Kušta et al. 2011, 2015). However, these studies are limited to large species, those that impede train operations and are easily observed (e.g., Singh et al. 2001). Some studies have depended on inquiries to railway staff about mortality data (Huijser et al. 2012), while others use anecdotal data from inhabitants, forest workers, naturalists, hunters, etc. (Singh et al. 2001).

\section{- Surveys by sidewalks along the railways}

Sidewalk surveys were mainly used in systematic studies by experienced technicians to detect mortality hotspots (Heske 2015; Peña and Llama 1997; Wells et al. 1999). Usually, these surveys aim to monitor and quantify all taxonomic groups (from small to large animals) independently of the mortality source (train collisions, entrapment in the track lines or electrocution) (Peña and Llama 1997; Wells et al. 1999).

\section{- Surveys by video vigilance}

In Alaska (USA), Rea et al. (2010) used movies from the YouTube video-sharing website, made mainly by employees of train companies and some anonymous people, to record the behavior of moose and other ungulates in the presence of trains. The use of video vigilance devices attached to trains, or cameras set on specific railway stretches, allowed continuous and clear recording of the animals' behavior toward trains (Kinley et al. 2003; Babińska-Werka et al. 2015). Video vigilance is particularly valuable in the winter in regions where snow cover and/or steep embankments impede the use of other methods (Rea et al. 2010). However, this method is expensive and thus has a limited observational range, and it cannot capture the entire vertebrate community in the railway vicinity.

\section{Standardization of Monitoring}

Studies should have standardized survey methods across different geographic areas, and combine several methods in order to reduce bias and contribute to better estimates of mortality on railways (Iuell et al. 2003; van der Grift et al. 2013). For instance, railway mortality should be presented as an index, reflecting the number of casualties $/ \mathrm{km} / \mathrm{year}$, and these results should include information on sampling effort and periodicity (Peña and Llama 1997; SCV 1996). In order to achieve consistency in the use of similar methods over temporal and spatial scales so that comparisons can be made, cooperation is required, and specialized personnel should be trained (Roedenbeck et al. 2007; Rytwinski et al. 2015). 


\section{How to Describe and Evaluate Hotspots of Mortality}

Most methods developed to identify mortality hotspots have been developed for roads (Gomes et al. 2009; Malo et al. 2004). One of the methods includes the assumption that the expected number of kills per segment $(\mathrm{km})$ follows a Poisson distribution, and hotspots correspond to segments where the number of casualties is higher than the upper 95\% confidence limit of the mean (Malo et al. 2004; Santos et al. 2015). The kernel method, identifies clusters of casualties by using a moving function to weight points of mortality within the influence of the function by their proximity to the location where density is being calculated (Ramp et al. 2005). The nearest neighbour hierarchical clustering identifies groups of points based on "nearest-neighbor-method" criteria (Gomes et al. 2009). Finally, the Getis-Ord Gi* statistic identifies hotspots by adding the number of casualties associated with a given segment of the road to the casualties of its neighboring segments, and compares that value with an overall expected distribution (Garrah et al. 2015). Integrating the information on rail sectors with high mortality rates with GIS mapping tools leads to the identification of the locations where mitigation measures (drift fences, rail passages, traffic regulation, etc.) should be applied (Costa et al. 2015). After obtaining the location of mortality hotspots, it is essential to verify the accuracy of the estimates, as overestimation can result in false hotspots (i.e., areas wrongly identified as having high mortality rates; Santos et al. 2015).

\section{Sources of Bias in Wildlife Mortality Estimates}

The reduction of mortality is one of the main aims of mitigation measures, hence high mortality rates and their locations need to be as accurate as possible (Guinard et al. 2012). As stated, even in systematic surveys, the number of carcasses found largely underestimates mortality because (1) only a subset of animals killed stay within the area that is searched by the observer; (2) many carcasses are removed by scavengers, or decomposed until the survey occurs; and (3) some dead animals remain undetected because of the observers failure (Korner-Nievergelt et al. 2015). Thus, to obtain unbiased estimates, the numbers obtained during surveys should be corrected by taking into account: (1) the proportion of animals killed in the area searched; (2) carcass persistence probability; and (3) searcher efficiency. In order to take into account these sources of bias, several mortality estimators were developed in wind farm studies (Korner-Nievergelt et al. 2015) and some have been applied to road casualties (Gerow et al. 2010; Teixeira et al. 2013), but rarely to railways, where these issues also apply.

The proportion of casualties (dead and/or injured that have not moved away) recorded at the search area can be obtained from the size and spatial distribution of the total area that can be searched, the spatial distribution of the carcasses, and the proportion of injured animals (still alive) that manage to move away. However, the 
spatial distribution of the carcasses depends on the type of obstacle they collided with, the size of the animal, and the wind speed at the time of collision (Korner-Nievergelt et al. 2015). Calculating the proportion of dead animals detected in the search area relative to the total area is rarely done because of the difficulties in estimating the variables involved (Teixeira et al. 2013).

Carcass persistence is the time a carcass stays on the rail or ground before it is removed by scavengers or has been severely decomposed, becoming undetectable to the observers. It depends mainly on the carcass size, the abundance and activity of scavengers, and temperature and humidity (Guinard et al. 2012; Santos et al. 2011).

Searcher efficiency, or detectability, is the probability that an observer actually finds a carcass in the search area. Detectability depends mostly on the survey method used, the experience and motivation of the observer, characteristics of the ground (vegetation density, ballast color), time of day, weather conditions, and type and size of the carcass. The method used for monitoring (e.g., by vehicle or on foot) greatly influences the detectability rates. For roads, Hels and Buchwald (2001) concluded that surveys by car detected between 7 and $67 \%$ of the amphibian carcasses that had been detected by surveys on foot and, similarly, Teixeira et al. (2013) reported a reduction in the detection rates from 1 to $27 \%$ for small and large animals, respectively. The observer's experience largely determines the probability of detectability: nevertheless, after several hours of work ( $>3 \mathrm{~h})$, there is a "saturation effect" that affects the observer performance. Motivation is also important, because a motivated observer (e.g., working on a thesis) may stop more often to collect data and see details that otherwise would have gone undetected (PVMC 2003). On railways, the color of the rock ballast is one of the main factors influencing carcass detectability. Generally, smooth terrain and light colors of rock increase detectability as does clear verges on both sides of the rail. Additionally, if the vegetation beyond the verge is sparse and short (or even absent), detectability increases. Another crucial aspect is the accessibility of the rail line, as well as the topography on its sides. Weather conditions also influence detection by altering visibility-for instance, detectability decreases on rainy or foggy days (e.g., Mathews et al. 2013). Intrinsic characteristics of the species, such as, the size, shape and color of a species, can compromise their identification (e.g., small carcasses with cryptic colors are more difficult to detect). These sources of error can be taken into account by mathematical estimators to recalculate a detectability function that is then used to correct the observed mortality estimates (Bernardino et al. 2013; Korner-Nievergelt et al. 2015), but this is not yet common practice in railway mortality studies. 


\section{How to Mitigate Wildlife Mortality in Railways?}

Over the last few decades, research and investment on mitigation measures to reduce wildlife mortality on roads have increased greatly (Jackson and Griffin 2000; Glista et al. 2009; Polak et al. 2014; Kociolek et al. 2015; Ward et al. 2015). In railways the efforts to increase wildlife safety have not been as considerable (van der Grift 1999; Dorsey et al. 2015), and these efforts have been concentrated mostly on mitigating the impacts on existing railways, ignoring the expansion of the high-speed railway network (Dorsey et al. 2015). An important difference between roads and railways is that in the latter, the speed and trajectory of a train cannot be changed to avoid collisions; therefore, mitigation measures must rely almost entirely on preventing the animals from entering or remaining on the train tracks.

\section{Crossing Structures}

The structures that facilitate wildlife crossing of railways can be part of the original engineering design of the infrastructure; these include culverts or bridges over roads or rivers, even when that was not their original purpose. At other times, these structures can become wildlife crossing locations with just minor adaptations, as happens with dry ledges. Alternatively, structures can be built with the specific goal of enabling movements across the linear infrastructure, usually designated as wildlife underpasses or overpasses.

Although crossing structures contribute to mitigating both mortality and barrier effects of linear infrastructures (Dorsey et al. 2015), their main role has been focused on barrier effects, ensuring connectivity through the landscapes crossed by railways and roads (Glista et al. 2009; Jackson and Griffin 2000; van der Ree et al. 2008). In this book, the application of crossing structures as a mitigation measure in railways is described in greater detail in Chap. 4. Here, we give a short description of the most frequently used crossing structures, and how they may help reduce wildlife mortality on railways.

Pipe culverts are small structures designed to let water flow under the railway, being regularly flooded during the rainy seasons. Pipe culverts form part of the design of most linear infrastructures and are sometimes used by small animals (Glista et al. 2009; Jackson and Griffin 2000). The efficiency of pipe culverts in reducing mortality would increase if it were associated with railway exclusion methods (see section below).

Box culverts are also designed for water drainage, and being larger than pipe culverts, often remain dry except in periods of heavy run-off. Box culverts are generally better as crossing structures than pipe culverts (Glista et al. 2009).

Culverts can be adapted before or after construction to facilitate their use by wildlife (Clevenger and Waltho 1999; Jackson and Griffin 2000; Rodríguez et al. 1996), namely by (1) including dry ledges, (2) modifying habitats at entrances, 
(3) adding drift fences, (4) avoiding culverts with steep slopes and large hydraulic jumps or steps; and (5) placing culverts in dry habitats (i.e., dry drainage culverts) and not only along streams. Flooded or very steep culverts may contribute little as wildlife crossing structures. Modifying culverts for wildlife crossing can represent one of the most economical measures to mitigate mortality on railways (Clevenger and Waltho 1999).

Amphibian tunnels are sometimes used in roads to facilitate crossing in areas where amphibians concentrate their movements (Glista et al. 2009), and they can be easily adapted to railways. Similarly, some tunnels can be designed for reptile crossing - reptile tunnels. Turtles and other small animals may often get caught between the rails, and a simple measure to prevent their becoming trapped can be the excavation of the rock ballast between pairs of railway sleepers, thus allowing animals to cross below the tracks (Dorsey et al. 2015; Pelletier et al. 2006).

Wildlife underpasses facilitate animal movement under linear infrastructures, and are generally located where railways cross watercourses and roads. However, underpasses can be specifically designed to be used by animals (Glista et al. 2009; Jackson and Griffin 2000). Therefore, underpasses show considerable differences in size, and provide variable crossing facilities. Underpasses can be very large (i.e., viaducts, expanded bridges), where railways cross large watercourses and extensive valleys, in which it is assumed that passage for wildlife is limited, or they can be relatively small when, for example, they are only meant to allow the access of local vehicles between agricultural fields. Small underpasses may provide limited use for wildlife crossing if they are associated with roads with considerable traffic, or when they are completely flooded by the watercourse.

Wildlife overpasses, also called "ecoducts," are structures mainly designed for large animal crossings, such as ungulates and large carnivores, and have often been used as a mitigation measure in large highways (Jackson and Griffin 2000). Overpasses with strips of natural vegetation are referred to as "green bridges," while the term "landscape connectors" is used for very wide overpasses designed to maintain landscape connectivity (Forman et al. 2003). Overpasses are often less confining than underpasses, facilitating the movement of a greater number of species, and they maintain ambient conditions more easily throughout the year (Glista et al. 2009; Jackson and Griffin 2000). The main drawback is their high cost of construction.

Crossing structures designed specifically for wildlife use should take into account the following characteristics to improve their effectiveness (Glista et al. 2009). However, as different species will favor different structure design, the best options must be planned for each particular case:

1. Location. The place where crossing structures are implemented is probably the single, most important factor for their effectiveness; thus, structures should be implemented where animal movements are more likely (Ando 2003; Jackson and Griffin 2000; Rodríguez et al. 1996; Yanes et al. 1995).

2. Dimensions. There is no reference size for passage structures, depending greatly on the target species. However, passages should have a relatively large diameter 
and openness (relative width-length of underpasses) and remain dry (at least partially) for most of the year (Baofa et al. 2006; Jackson and Griffin 2000; Yanes et al. 1995). Some species, such as rabbits, seem to prefer underpasses where it is possible to see the opposite end (Rosell et al. 1997).

3. Substrate, moisture, temperature, and light. These characteristics of crossing structures will influence their use by animals (Glista et al. 2009; Jackson and Griffin 2000; Rosell et al. 1997). The set of adequate conditions can be species-specific, but in general animals prefer crossing structures with a natural substrate, no temperature differences, and natural light (avoiding dark or artificially lit structures). Amphibians in particular require moist conditions.

4. Approaching habitat. The habitat near passing structures should be attractive to animals; in particular, the presence of covers, or their absence, may determine the use of crossing structures by some species (Baofa et al. 2006; Jackson and Griffin 2000; Rodríguez et al. 1996; Yanes et al. 1995).

5. Guiding structures. Fences and barrier walls guiding wildlife to crossing structures maximize their effectiveness (Jackson and Griffin 2000). For example, in Florida, the implementation of a barrier wall in conjunction with a culvert system reduced the road mortality of vertebrate species (excluding hylid treefrogs) by $94 \%$ (Dodd et al. 2004).

6. Disturbance. The use of crossing structures by humans and vehicles should be reduced as much as possible (Baofa et al. 2006; Clevenger and Waltho 2000). Noisy underpasses are likely to be avoided by more sensitive species (Jackson and Griffin 2000).

7. Interspecific interactions. The regular use of passages by predators may discourage their use by potential prey species (Clevenger and Waltho 1999, 2000). Habitats frequently used by predators of the target species should then be avoided-namely, the preferred hunting grounds and core areas of the home range of predators.

Although crossing structures can strongly contribute to reducing the mortality of non-flying animals, they are less effective in preventing collisions of birds and bats with trains, as these animals fly above the railway (Tremblay and St. Clair 2009). The exception to this are the large railway bridges and viaducts going over watercourses and valleys, in which the large size of the crossing structure facilitates the movement of birds and bats beneath the railway (Tremblay and St. Clair 2009).

\section{Structures that Restrict Wildlife Access to Railways}

One of the most effective measures for reducing wildlife mortality in railways is the implementation of structures that prevent crossing or, in the case of flying animals, forcing the crossing above the trains and overhead wires (Dorsey et al. 2015; Glista et al. 2009; van der Grift 1999). However, the application of measures that restrict movements will inevitably increase barrier effects, unless accompanied by adequate 
crossing structures (Dorsey et al. 2015; Jackson and Griffin 2000; van der Grift 1999). Railways have already been recognized as potential ecological barriers, namely for large mammals (Ito et al. 2013, and see also Chap. 14), a similar and cumulative effect with that of roads (see Chap. 4). Therefore, the generalized use of barriers along railways should be discouraged (Dorsey et al. 2015; Ito et al. 2013; Jackson and Griffin 2000). Barriers should be erected only along the stretches with high incidence of wildlife-train collisions, i.e., mortality hotspots.

Exclusion fences are currently considered to be the most effective means to restrict wildlife access to railways (Ito et al. 2013; van der Grift 1999) being, probably, the best cost-effective measure to mitigate wildlife mortality in the long run (Dorsey et al. 2015). However, fences may be less effective for species capable of climbing, jumping over, or digging under them (Jackson and Griffin 2000). When fencing is used, it is crucial to provide escapes to avoid animals becoming trapped between fences on both sides of the railway (Jackson and Griffin 2000). One-way gates or returning ramps should be regularly installed in places where animal crossing is more intense. Short retaining walls can be efficient barriers for reptiles, amphibians and small mammals (Jackson and Griffin 2000). While leaving a small passage close to the ground (like raising the lower wire of fences) may reduce the barrier effect for smaller and more agile species, it still prevents the access of livestock to the railway (Ito et al. 2013).

Olfactory repellents consist of chemicals applied on structures or on the vegetation along the railway (e.g., Andreassen et al. 2005; Kušta et al. 2015). The aim of olfactory repellents is to drive animals away from the structure or to keep them more alert, and thus more prone to evade approaching trains. There are several types of olfactory repellents used for scent-marking, namely synthetic products of predator substances (Lutz 1994; Andreassen et al. 2005). In Norway, Andreassen et al. (2005) sprayed a repellant on trees and bamboo canes at $5 \mathrm{~m}$ intervals along the railway, and found that it had an effect on reducing moose casualties, although with variable efficiency. In the Czech Republic, the application of odor repellents reduced overall animal mortality on roads and railways, but it was not effective for reptiles or amphibians (Kušta et al. 2015). In addition, repellants seem to be less effective at low temperatures (Castiov 1999; Kušta et al. 2015).

Sound signalling and sound-barriers can represent a promising alternative mitigation measure, especially if they do not greatly limit movements across railways. Sound signalling consists of warning animals of approaching trains (Babińska-Werka et al. 2015), while sound barriers are mostly intended to keep animals off the railway. Stationary systems can be mounted in critical areas, using a motion-activated sensor triggering an audio (and sometimes also visual) stimulus to frighten the animals. Alternatively, stationary systems can be activated only when there is a train coming. Electronic systems can also be installed on the front of the trains. Displayed sounds can be audible or ultrasonic to humans depending on the target species. For instance, trains equipped with ultrasonic wildlife warning contributed to the reduction of moose-train collisions along a railway in Canada (Muzzi and Bisset 1990). Babińska-Werka et al. (2015) studied the effectiveness of an acoustic wildlife warning device in reducing casualties along railways. The sound 
sequence in their devices combined: (1) the alarm call of the jay Garrulus glandarius; (2) the sound of a frightened brown hare Lepus europaeus; (3) a dog Canis familiaris growling and barking; (4) a wolf Canis lupus howling; (5) squeal of a wild boar Sus scrofa; and (6) warning sounds of roe deer Capreolus capreolus (Babińska-Werka et al. 2015). These natural warning calls should promote the alerted behavior of wild animals thus increasing their escape time from oncoming trains. The sound warning devices may be placed along critical railway stretches (e.g., in Babińska-Werka et al. 2015 they were separated by $70 \mathrm{~m}$ ), being activated by a signal sent by the automatic railway system in advance of a train $(30 \mathrm{~s}$ to $3 \mathrm{~min}$ ). The use of sound signalling increased the proportion of wildlife escaping from the tracks, with individuals reacting faster and showing no evidence of habituation to the warning signals (Babińska-Werka et al. 2015). Multiple horn blasts have been used by train drivers to effectively flush animals (mostly ungulates) from rails (Helldin et al. 2011).

Physical barriers such as trees, diversion poles, flight diverters, or noise barriers, may contribute to the reduction of mortality, especially among birds (Bard et al. 2002; Jacobson 2005; Kociolek et al. 2015; Zuberogoitia et al. 2015) and bats (Ward et al. 2015). Pole barriers may represent a relatively inexpensive mitigation measure, as they can be effective in diverting the flight of medium- or large-sized birds above the poles (Zuberogoitia et al. 2015). The pole barriers used by Zuberogoitia et al. (2015) consisted of: (1) gray PVC poles $2 \mathrm{~m}$ high and $8 \mathrm{~cm}$ wide regularly separated by 1 or $2 \mathrm{~m}$, and some had shredded pieces of coloured paper (white or orange) attached to the top of the pole, or (ii) tree trunks $(20-26 \mathrm{~cm}$ diameter and $350 \mathrm{~cm}$ height) separated by $1 \mathrm{~m}$.

Trees and other hedgerow vegetation can work as a barrier, preventing access to railways, especially to large animals, and forcing birds and bats to fly above the trains. However, this habitat can also become a refuge or foraging site for some species (e.g., small birds and mammals), thus potentially working as an ecological trap by attracting wildlife to the proximity of the railway.

Lighting and reflectors have been mainly tested on roads as wildlife deterrents. This mitigation measure is used mostly for nocturnal species, and may reflect the lights of vehicles or, alternatively, flash signals before an oncoming train. Lights and reflectors may be combined with sound signalling to provide a faster response. Nevertheless, lights should not be too intense in order to avoid blinding the animals, whose reaction will probably be to stay still, thus remaining on the tracks.

\section{Habitat and Wildlife Population Management}

Lower numbers of wildlife species near railways can be achieved by controlling populations (e.g., selective hunting, trapping), or by habitat modification. Changes in habitat structure along railway verges may also increase animals' capability to detect and evade the train. 
Habitat management includes vegetation mowing or pruning at railway verges, or the removal of specific fruiting plants (Andreassen et al. 2005; Eriksson 2014; Jacobson 2005). Vegetation removal (forest clearing) was successfully employed along a railway in Norway, achieving a reduction in about half the number of moose casualties (Andreassen et al. 2005; Jaren et al. 1991). It combined a decreased attractiveness of verges for wildlife, hence leading to animals spending less time foraging close to railways, and higher visibility, providing a shorter reaction time by animals. However, Helldin et al. (2011) and Eriksson (2014) found the opposite effect, suggesting that tree-clearing may increase moose and roe deer train collisions in Sweden, as areas cleared after mowing offer attractive foraging opportunities for some species. In another study using Before-After-Control-Impact (BACI), tree clearance had no effect on the frequency of wildlife collisions (Eriksson 2014). Helldin et al. (2011) showed that vegetation management requires regular maintenance; otherwise, mortality may return to previous levels after plant growth. These authors mention that tree-clearance can reduce collisions if applied frequently, but it can increase collisions if applied at intervals greater than 3-4 years. Finally, it is relevant to mention that habitat management (vegetation removal) can limit the movements of some species, hence increasing barrier effects; for example, small vertebrates are generally reluctant to cross large open spaces due to greater exposure to predators (Hunt et al. 1987; Yanes et al. 1995).

Population control of a particular species may sometimes be used to reduce its numbers near railways. This method should only be applied on very common species, or those that can compromise human safety due to collisions. This method has been used to prevent collision with vehicles on roads (Glista et al. 2009), but its use in railways may not be as necessary since most animals will not affect trains' movements.

Supplemental feeding stations placed far from railways may influence animal movement, keeping animals away from linear infrastructures and thus contributing to reducing mortality (Andreassen et al. 2005; Wood and Wolfe 1988).

\section{Reducing Train Speed}

Greater speeds are undoubtedly associated with a greater risk of wildlife mortality on roads as well as on, railways (e.g., Cserkész and Farkas 2015; Frikovic et al. 1987). Thus, train speed moderation, at least at critical points (mortality hotspots) and during periods of higher crossing movements (e.g., migration), should contribute to reducing animal mortality, as slower trains have fewer collisions (Becker and Grauvogel 1991; Belant 1995). 


\section{Collision and Electrocution in Overhead Wires}

Flying animals may collide or be electrocuted in the overhead wires that provide electrical energy to trains - the catenary (SCV 1996). Thus, specific mitigation measures should be taken whenever high levels of mortality are expected or identified. These measures are similar to those used to prevent collision and electrocution in powerlines (Bevanger 1994; Barrientos et al. 2011). Additionally, the tubular poles often used to support the overhead wires can cause death if uncapped, especially among cavity nesting birds (Malo et al. 2016). The compulsory use of capped poles can easily avoid this problem, since it prevents birds from falling inside the poles.

\section{Evaluating the Effectiveness of Mortality Mitigation Measures}

Along with adequate planning for railway corridors, which accounts for the expected impacts on wildlife, another fundamental and final step to reduce the negative effects of railways is a thorough evaluation of the effectiveness of the mitigation measures (Grilo et al. 2010; Glista et al. 2009; van der Grift et al. 2013). Poor mitigation measures, which do little to reduce wildlife mortality, represent a waste of valuable resources. Moreover, some structures may reduce animal movement, disrupt landscape connectivity, or have negative implications for erosion and grazing.

Guidelines for evaluating the effectiveness of road mitigation measures have been proposed for roads (van der Grift et al. 2013; Rytwinski et al. 2015; van der Grift and van der Ree 2015), but since no similar research has been done specifically for railways, one can consider the guidelines for roads as a starting point.

Step 1 Identify the species requiring mitigation measures and determine the specific goals for them.

Step 2 Select the species (from the targeted species list) that will be used for evaluation.

Step 3 Select the best measures of interest, i.e., those that are most closely related to the aim of the mitigation (e.g., casualty rate, number of crossings, population trend).

Step 4 Select the adequate study design, including a spatial and temporal sampling strategy. Whenever possible, the best study design is a replicated BACI at mitigation sites (where measures were taken) and control sites (with similar characteristics but where no mitigation measures were applied).

Step 5 Determine the best sampling scheme, including the number of sites, the frequency of visits, the monitoring methods, and the number of replicates. 
Step 6 Select the appropriate sites, both mitigated and control. This includes choosing the best spatial scale for the evaluation study.

Step 7 Select the best covariates to measure (e.g., railway characteristics, type of fences, type of culvert, presence of noise barriers, human disturbance, presence of vegetation on verges, train speed, surrounding landscape characteristics).

Step 8 Select the most suitable survey methods, namely preferring methods that monitor several species simultaneously, and choosing ways to reduce bias.

Step 9 Determine the costs and feasibility of the evaluation study, and act in agreement by implementing the necessary adaptations.

It is crucial to do a research-based evaluation of the success of mitigation measures, which should be of a broad scope that includes wildlife mortality and movements, landscape constraints, and safety. Finally, as indirect ecological consequences of many mitigation measures are poorly understood and often neglected, they should be taken into account in the overall evaluation process of their effectiveness.

Acknowledgments S.M. Santos and R. Lourenço were supported by post-doctoral Grants of the Fundação para a Ciência e Tecnologia (FCT; SFRH/BPD/70124/2010 and SFRH/BPD/78241/2011, respectively).

\section{References}

Ando, C. (2003). The relationship between deer-train collisions and daily activity of the sika deer, Cervus nippon. Mammal Study, 28, 135-143.

Andreassen, H. P., Gundersen, H., \& Storaasthe, T. (2005). The effect of scent-marking, forest clearing and supplemental feeding on moose-train collisions. Journal of Wildife Management, 69, 1125-1132.

Babińska-Werka, J., Krauze-Gryz, D., Wasilewski, M., \& Jasińska, K. (2015). Effectiveness of an acoustic wildlife warning device using natural calls to reduce the risk of train collisions with animals. Transportation Research D, 38, 6-14.

Baofa, Y., Huyin, H., Yili, Z., Le, Z., \& Wanhong, W. (2006). Influence of the Qinghai-Tibetan railway and highway on the activities of wild animals. Acta Ecologica Sinica, 26, 3917-3923.

Bard, A. M., Smith, H. T., Egensteiner, E. D., Mulholland, R., Harber, T. V., Heath, G. W., et al. (2002). A simple structural method to reduce road-kills of royal terns at bridge sites. Wildlife Society Bulletin, 30, 603-605.

Barrientos, R., Alonso, J. C., Ponce, C., \& Palacín, C. (2011). Meta-analysis of the effectiveness of marked wire in reducing avian collisions with power lines. Conservation Biology, 25, 893-903.

Becker, E. F., \& Grauvogel, C. A. (1991). Relationship of reduced train speed on moose-train collisions in Alaska. Alces, 27, 161-168.

Belant, J. L. (1995). Moose collisions with vehicles and trains in Northeastern Minnesota. Alces, $31,1-8$.

Bernardino, J., Bispo, R., Costa, H., \& Mascarenhas, M. (2013). Estimating bird and bat fatality at wind farms: A practical overview of estimators, their assumptions and limitations. New Zeland Journal of Zoology, 40, 63-74. 
Bevanger, K. (1994). Bird interactions with utility structures: Collision and electrocution, causes and mitigating measures. Ibis, 136, 412-425.

Castiov, F. (1999). Testing potential repellents for mitigation of vehicle-induced mortality of wild ungulates in Ontario. Ph.D. thesis Dissertation, Laurentian University, Sudbury.

Clevenger, A. P., \& Waltho, N. (1999). Dry drainage culvert use and design considerations for small- and medium-sized mammal movement across a major transportation corridor. In G. L. Evink, P. Garrett, \& D. Zeigler (Eds.), Proceedings of the third international conference on wildlife ecology and transportation (pp. 263-277). Tallahassee, FL: Florida Department of Transportation.

Clevenger, A. P., \& Waltho, N. (2000). Factors influencing the effectiveness of wildlife underpasses in Banff National Park, Alberta, Canada. Conservation Biology, 14, 47-56.

Costa, A. S., Ascensão, F., \& Bager, A. (2015). Mixed sampling protocols improve the cost-effectiveness of roadkill surveys. Biodiversity and Conservation, 24, 2953-2965.

Cserkész, T., \& Farkas, J. (2015). Annual trends in the number of wildlife-vehicle collisions on the main linear transport corridors (highway and railway) of Hungary. North-Western Journal of Zoology, 11, 41-50.

Dodd, C. K., Jr., Barichivich, W. J., \& Smith, L. L. (2004). Effectiveness of a barrier wall and culverts in reducing wildlife mortality on a heavily traveled highway in Florida. Biological Conservation, 118, 619-631.

Dorsey, B. (2011). Factors affecting bear and ungulate mortalities along the Canadian Pacific Railroad through Banff and Yoho National Parks. Master's thesis, Montana State University.

Dorsey, B., Olsson, M., \& Rew, L. J. (2015). Ecological effects of railways on wildlife. In R. van der Ree, D. J. Smith, \& C. Grilo (Eds.), Handbook of road ecology (pp. 219-227). West Sussex: Wiley.

Eriksson, C. (2014). Does tree removal along railroads in Sweden influence the risk of train accidents with moose and roe deer? Dissertation, Second cycle, A2E. Grimsö och Uppsala: SLU, Department of Ecology, Grimsö Wildlife Research Station.

Forman, R. T. T., Sperling, D., Bissonette, J. A., Clevenger, A. P., Cutshall, C. D., Dale, V. H., et al. (2003). Road ecology: Science and solutions. Washington, DC: Island Press.

Frikovic, A., Ruff, R. L., Cicnjak, L., \& Huber, D. (1987). Brown bear mortality during 1946-85 in Gorski Kotar, Yugoslavia. In International conference on bear research and management (Vol. 7, pp. 87-92).

Garrah, E., Danby, R. K., Eberhardt, E., Cunnington, G. M., \& Mitchell, S. (2015). Hot spots and hot times: Wildlife road mortality in a regional conservation corridor. Environmental Management, 56, 874-889.

Gerow, K., Kline, N. C., Swann, D. E., \& Pokorny, M. (2010). Estimating annual vertebrate mortality on roads at Saguaro National Park, Arizona. Human and Wildlife Interactions, 4, 283-292.

Glista, D. J., DeVault, T. L., \& DeWoody, J. A. (2009). A review of mitigation measures for reducing wildlife mortality on roadways. Landscape and Urban Planning, 91, 1-7.

Gomes, L., Grilo, C., Silva, C., \& Mira, A. (2009). Identification methods and deterministic factors of owl roadkill hotspot locations in Mediterranean landscapes. Ecological Research, 24, 355370.

Grilo, C., Bisonette, J. A., \& Cramer, P. C. (2010). Mitigation measures to reduce impacts on biodiversity. In S. R. Jones (Ed.), Highways: Construction, management, and maintenance (pp. 73-114). Hauppauge: Nova Science Publishers.

Guinard, E., Julliard, R., \& Bardraud, C. (2012). Motorways and bird traffic casualties: Carcass surveys and scavenging bias. Biological Conservation, 147, 40-51.

Gundersen, H., Andreassen, H. P., \& Storaas, T. (1998). Spatial and temporal correlates to Norwegian moose-train collisions. Alces, 34, 385-394.

Gunson, K. E., Mountrakis, G., \& Quackenbush, L. J. (2011). Spatial wildlife-vehicle collision models: A review of current work and its application to transportation mitigation projects. Journal of Environmental Management, 92, 1074-1082. 
Helldin, J. O., Seiler, A., Olsson, M., \& Norin, H. (2011). Klövviltolyckor på järnväg: kunskapsläge, problemanalys och åtgärdsförslag. Ungulate-train collisions in Swedenreview, GIS-analyses and train-drivers experiences (in Swedish). Sweden: Trafikverket.

Hels, T., \& Buchwald, E. (2001). The effect of road kills on amphibian populations. Biological Conservation, 99, 331-340.

Heske, E. J. (2015). Blood on the tracks: Track mortality and scavenging rate in urban nature preserves. Urban Naturalist, 4, 1-13.

Huijser, M. P., Begley, J. S., \& van der Grift, E. A. (2012). Mortality and live observations of wildlife on and along the Yellowhead Highway and the Railroad through Jasper National Park and Mount Robson Provincial Park, Canada. Salmo Consulting Inc., On behalf of Kinder Morgan Canada, Calgary, Canada.

Hunt, A., Dickens, H. J., \& Whelan, R. J. (1987). Movement of mammals through tunnels under railway lines. Australian Zoology, 24, 89-93.

Ito, T. Y., Lhagvasuren, B., Tsunekawa, A., Shinoda, M., Takatsuki, S., Buuveibaatar, B., et al. (2013). Fragmentation of the habitat of wild ungulates by anthropogenic barriers in Mongolia. PLOS ONE, 8, e56995.

Iuell, B., Bekker, G. J., Cuperus, R., Dufek, J., Fry, G., Hicks, C., et al. (2003). Wildlife and traffic: A European handbook for identifying conflicts and designing solutions. Utrecht: KNNV Natural History Publishers.

Jackson, S. D., \& Griffin, C. R. (2000). A strategy for mitigating highway impacts on wildlife. In T. A. Messmer \& B. West (Eds.), Wildlife and highways: Seeking solutions to an ecological and socio-economic dilemma (pp. 143-159). Bethesda: The Wildlife Society.

Jacobson, S. L. (2005). Mitigation measures for highway-caused impacts to birds. PSW-GTR-191. USDA Forest Service General Technical Report.

Jaren, V., Andersen, R., Ulleberg, M., Pedersen, P., \& Wiseth, B. (1991). Moose-train collisions: The effects of vegetation removal with a cost-benefit analysis. Alces, 27, 93-99.

Kinley, T. A., Page, H. N., \& Newhouse, N. J. (2003). Use of infrared camera video footage from a wildlife protection system to assess collision-risk behavior by deer in Kootenay National Park, British Columbia. Invermere, BC: Sylvan Consulting Ltd.

Kociolek, A., Grilo, C., \& Jacobson, S. (2015). Flight doesn't solve everything: Mitigation of road impacts on birds. In R. van der Ree, D. J. Smith, \& C. Grilo (Eds.), Handbook of road ecology (pp. 281-289). West Sussex: Wiley.

Korner-Nievergelt, F., Behr, O., Brinkmann, R., Etterson, M. A., Huso, M. M. P., Dalthorp, D., et al. (2015). Mortality estimation from carcass searches using the R-package carcass-A tutorial. Wildlife Biology, 21, 30-43.

Kornilev, Y., Price, S., \& Dorcas, M. (2006). Between a rock and a hard place: Responses of eastern box turtles (Terrapene carolina) when trapped between railroad tracks. Herpetological Reviews, 37, 145-148.

Kušta, T., Holá, M., Keken, Z., Ježek, M., Zíka, T., \& Hart, V. (2014). Deer on the railway line: Spatiotemporal trends in mortality patterns of roe deer. Turkish Journal of Zoology, 38, 479485.

Kušta, T., Ježek, M., \& Keken, Z. (2011). Mortality of large mammals on railway tracks. Scientia Agriculturae Bohemica, 42, 12-18.

Kušta, T., Keken, Z., Ježek, M., \& Kůta, Z. (2015). Effectiveness and costs of odor repellents in wildlife-vehicle collisions: A case study in Central Bohemia, Czech Republic. Transportation Research Part D, 38, 1-5.

Lutz, W. (1994). Trial results of the use of a "Duftzaun ${ }^{\circledR}$ ", (scent fence) to prevent game losses due to traffic accidents. Zeitschrift für Jagdwissenschaft, 40, 91-108.

Malo, J. E., García de la Morena, E. L., Hervás, I., Mata, C., \& Herranz, J. (2016). Uncapped tubular poles along high-speed railway lines act as pitfall traps for cavity nesting birds. European Journal of Wildlife Research, 62, 483-489.

Malo, J. E., Suarez, F., \& Diez, A. (2004). Can we mitigate animal-vehicle accidents using predictive models? Journal of Applied Ecology, 41, 701-710. 
Mathews, F., Swindells, M., Goodhead, R., August, T. A., Hardman, P., Linton, D. M., et al. (2013). Effectiveness of search dogs compared with human observers in locating bat carcasses at wind-turbine sites: A blinded randomized trial. Wildlife Society Bulletin, 37, 34-40.

Muzzi, P. D., \& Bisset, A. R. (1990). Effectiveness of ultrasonic wildlife warning devices to reduce moose fatalities along railway corridors. Alces, 26, 37-43.

Pelletier, S. K., Carlson, L., Nein, D., \& Roy, R. D. (2006). Railroad crossing structures for spotted turtles: Massachusetts Bay Transportation Authority-Greenbush rail line wildlife crossing demonstration project. In C. L. Irwin, P. Garrett, \& K. P. McDermott (Eds.), Proceedings of the 2005 international conference on ecology and transportation (pp. 414-425). Raleigh, NC: Center for Transportation and the Environment, North Carolina State University.

Peña, O. L., \& Llama, O. P. (1997). Mortalidad de aves en un tramo de linea de ferrocarril (32 p). Grupo Local SEO-Sierra de Guadarrama, Spain.

Polak, T., Rhodes, J. R., Jones, D., \& Possingham, H. P. (2014). Optimal planning for mitigating the impacts of roads on wildlife. Journal of Applied Ecology, 51, 726-734.

PVMC. (2003). Mortalidad de vertebrados en carreteras. Proyecto provisional de seguimiento de la mortalidad de vertebrados en carreteras. Coordinadora de Organizaciones de Defensa Ambiental. Documentos Técnicos de Conservación S.C.V., 4.

Ramp, D., Caldwell, J., Edwards, K., Warton, D., \& Croft, D. (2005). Modelling of wildlife fatality hotspots along the Snowy Mountain Highway in New South Wales, Australia. Biological Conservation, 126, 474-490.

Rea, R. V., Child, K. N., \& Aitken, D. A. (2010). Youtube ${ }^{\mathrm{TM}}$ insights into moose-train interactions. Alces, 46, 183-187.

Rodríguez, A., Crema, G., \& Delibes, M. (1996). Use of non-wildlife passages across a high speed railway by terrestrial vertebrates. Journal of Applied Ecology, 33, 1527-1540.

Roedenbeck, I. A., Fahrig, L., Findlay, C. S., Houlahan, J. E., Jaeger, J. A. G., Klar, N., et al. (2007). The Rauischholzhausen agenda for road ecology. Ecology and Society, 12, 11.

Rose, P., \& Baillie, S. (1989). The effects of collisions with overhead lines on British birds: An analysis of ringing recoveries. Research Report, 42. British Trust for Ornithology.

Rosell, C., Parpal, J., Campeny, R., Jove, S., Pasquina, A., \& Velasco, J. M. (1997). Mitigation of barrier effect of linear infrastructures on wildlife. In K. Canters (Ed.), Habitat fragmentation \& infrastructure (pp. 367-372). Proceedings of the International Conference on Habitat Fragmentation, Infrastructure and the Role of Ecological Engineering. Delft, The Netherlands: Ministry of Transport, Public Works and Water Management.

Rytwinski, T., van der Ree, R., Cunnington, G. M., Fahrig, L., Findlay, C. S., Houlahan, J., et al. (2015). Experimental study designs to improve the evaluation of road mitigation measures for wildlife. Journal of Environmental Management, 154, 48-64.

Santos, S. M., Carvalho, F., \& Mira, A. (2011). How long do the dead survive on the Road? Carcass persistence probability and implications for road-kill monitoring surveys. PLoS ONE, 6, e25383.

Santos, S. M., Marques, J. T., Lourenço, A., Medinas, D., Barbosa, A. M., Beja, P., et al. (2015). Sampling effects on the identification of roadkill hotspots: implications for survey design. Journal of Environmental Management, 162, 87-95.

S. C. V. (1996). Mortalidad de vertebrados en líneas de ferrocarril. Documentos Técnicos de Conservacion SCV 1, Sociedad Conservación Vertebrados, Madrid.

Seiler, A., \& Helldin, J.-O. (2006). Mortality in wildlife due to transportation. In J. Davenport \& J. L. Davenport (Eds.), The ecology of transportation: Managing mobility for the environment (pp. 165-189). Dordrecht: Springer.

Singh, A. K., Kumar, A., Mookerjee, A., \& Menon, V. (2001). A scientific approach to understanding and mitigating elephant mortality due to train accidents in Rajaji National Park. An Occasional Report no 3 by Wildlife Trust of India and the International Fund for Animal Welfare of a Rapid Action Project on understanding and mitigating the problem of elephant mortality due to train hits.

Stevens, B. S., \& Dennis, B. (2013). Wildlife mortality from infrastructure collisions: Statistical modelling of count data from carcass surveys. Ecology, 94, 2087-2096. 
Teixeira, F. Z., Coelho, A. V. P., Esperandio, I. B., \& Kindel, A. (2013). Vertebrate road mortality estimates: Effects of sampling methods and carcass removal. Biological Conservation, 157, 317-323.

Tremblay, M. A., \& St. Clair, C. C. (2009). Factors affecting the permeability of transportation and riparian corridors to the movements of songbirds in an urban landscape. Journal of Applied Ecology, 46, 1314-1322.

van der Grift, E. A. (1999). Mammals and railroads: Impacts and management implications. Lutra, 42, 77-98.

van der Grift, E. A., \& Kuijsters, H. M. J. (1998). Mitigation measures to reduce habitat fragmentation by railway lines in the Netherlands. In G. L. Evink, P. Garrett, D. Zeigler, \& J. Berry (Eds.), Proceedings of the international conference on wildlife ecology and transportation (pp. 166-170). Tallahassee, FL: Florida Department of Transportation.

van der Grift, E. A., \& van der Ree, R. (2015). Guidelines for evaluation use of wildlife crossing structures. In R. van der Ree, D. J. Smith, \& C. Grilo (Eds.), Handbook of road ecology (pp. 119-128). West Sussex: Wiley.

van der Grift, E. A., van der Ree, R., Fahrig, L., Findlay, S., Houlahan, J., Jaeger, J. A. G., et al. (2013). Evaluating the effectiveness of road mitigation measures. Biodiversity and Conservation, 22, 425-448.

van der Ree, R., Clarkson, D. T., Holland, K., Gulle, N., \& Budden, M. (2008). Review of mitigation measures used to deal with the issue of habitat fragmentation by major linear infrastructure. Report for Department of Environment, Water, Heritage and the Arts (DEWHA), Contract No. 025/2006, Published by DEWHA.

Ward, A. I., Dendy, J., \& Cowan, D. P. (2015). Mitigating impacts of roads on wildlife: An agenda for the conservation of priority European protected species in Great Britain. European Journal of Wildlife Research, 61, 199-211.

Wells, P., Woods, J. G., Bridgewater, G., \& Morrison, H. (1999). Wildlife mortalities on railways: Monitoring methods and mitigation strategies, Revelstoke, BC. Unpublished report.

Wood, P., \& Wolfe, M. L. (1988). Intercept feeding as a means of reducing deer-vehicle collisions. Wildlife Society Bulletin, 16, 376-380.

Yanes, M., Velasco, J. M., \& Suaréz, F. (1995). Permeability of roads and railways to vertebrates: The importance of culverts. Biological Conservation, 7, 217-222.

Zuberogoitia, I., del Real, J., Torres, J. J., Rodríguez, L., Alonso, M., de Alba, V., et al. (2015). Testing pole barriers as feasible mitigation measure to avoid bird vehicle collisions (BVC). Ecological Engineering, 83, 144-151.

Open Access This chapter is licensed under the terms of the Creative Commons Attribution 4.0 International License (http://creativecommons.org/licenses/by/4.0/), which permits use, sharing, adaptation, distribution and reproduction in any medium or format, as long as you give appropriate credit to the original author(s) and the source, provide a link to the Creative Commons license and indicate if changes were made.

The images or other third party material in this chapter are included in the chapter's Creative Commons license, unless indicated otherwise in a credit line to the material. If material is not included in the chapter's Creative Commons license and your intended use is not permitted by statutory regulation or exceeds the permitted use, you will need to obtain permission directly from the copyright holder.

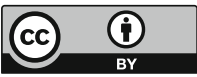

